\title{
Correction
}

\section{Correction: Kerimoglu et al., Histone-Methyltransferase MLL2 (KMT2B) Is Required for Memory Formation in Mice}

In the article "Histone-Methyltransferase MLL2 (KMT2B) Is Required for Memory Formation in Mice" by Cemil Kerimoglu, Roberto Carlos Agis-Balboa, Andrea Kranz, Roman Stilling, Sanaz Bahari-Javan, Eva Benito-Garagorri, Rashi Halder, Susanne Burkhardt, Adrian Francis Stewart, and Andre Fischer, which appeared on pages 3452-3464 of the February 20, 2013 issue, the sequence and the $\mathrm{T}_{\mathrm{m}}$ value for "Acot4 Forward" primer used in ChIP-qPCR was missing from Table 2. The following are the sequence and the $\mathrm{T}_{\mathrm{m}}$ value of the above-mentioned primer: gctgtagcatccagggaagt 63.2.

Moreover, in Table 3, the following gene symbols with their corresponding gene names should have also been written in bold since their downregulation in dentate gyrus of Kmt2b cKO mice was confirmed by qPCR as well (see Fig. 4A): Adcy5, Ptgr1, Prkra, Gabrg3, Car4, Ckap4, Stxbp2, Sypl2, Gkap1, Tpm4, E2f1. Additionally, the following gene symbol with its corresponding name should also be written in italic, since its downregulation was also confirmed by qPCR both in dentate gyrus and CA of Kmt2b cKO mice: Oxr1.

DOI: 10.1523/JNEUROSCI.1180-13.2013 